\title{
THE DEVELOPMENT OF THE CAPACITOR INDUSTRY AND ITS POSITION IN WORLD MARKETS
}

\author{
PETER D. DRIVER \\ Plessey Capacitors, Bathgate, West Lothian, Scotland
}

(Received September 1, 1977)

\begin{abstract}
This article sets out the existing position in world markets of the capacitor industry and discusses its development both technically and commercially over the next few years. It examines the major component product groups within the capacitor industry and indicates their relative importance in the total capacitor market and also their individual development trends.

The external and internal pressures exerted on the capacitor industry are examined and their relative importance in connection with the development of the industry are disclosed.
\end{abstract}

\section{INTRODUCTION}

This article discusses the general market position of major capacitor product groups in world markets and examines the areas of growth within these product groups. The various internal and external pressures which control the direction of development of the capacitor industry are highlighted and possible future commercial and technical development trends are discussed.

\section{THE CAPACITOR MARKET WORLD WIDE}

In the relatively few years since man first made a sandwich of electrodes and dielectric material, the capacitor industry has grown into a multi billion dollar world wide industry and has divided into major product groups for specialist applications. (See Ref. 1 for a technical survey of the various types of capacitors.) It is an industry which has had a slow technological development with inventions and developments mainly being variations on a theme revolving around changes in construction techniques rather than the changing of the basic materials used.

Aluminium is still the major electrode material and it is only in the last fifteen to twenty years that paper has been replaced as the major dielectric material by plastic films. The introduction of plastic films as a dielectric has probably brought in the greatest advance in capacitor technology in the form of dry, non-impregnated capacitors. This has lead to a complete revolution of manufacturing techniques leading to the production of smaller, cheaper capacitors by more fully automatic means.

The growth of the modern capacitor industry was triggered by the huge leap forward in electronic developments that commenced in World War II. With the return of peace and the development of electronically orientated consumer products plus the development of entire new fields of electronics, the world demand for capacitors has continued to rise dramatically.

Unfortunately for the capacitor manufacturer, the industry is violently affected by the peaks and troughs in world trade which in turn, causes huge variations in component demand from the consumer industry. ${ }^{2}$ (See Figures 1,2 ). This in turn causes great difficulty in predicting the forward requirements of the market and leads to component shortages in times of upswings in the market and large surplus manufacturing capacity during the downswings.

As a result of this, there is often a reticence to invest the large amounts of capital required to lay down new capacitor plant. It is therefore in the interests of both the capacitor manufacturer and his customers to endeavour to control these market surges. Some of the steps that are being taken will be discussed later in this article. Relative data for world markets ${ }^{3}$ for capacitor product types is shown in Figure 3. 


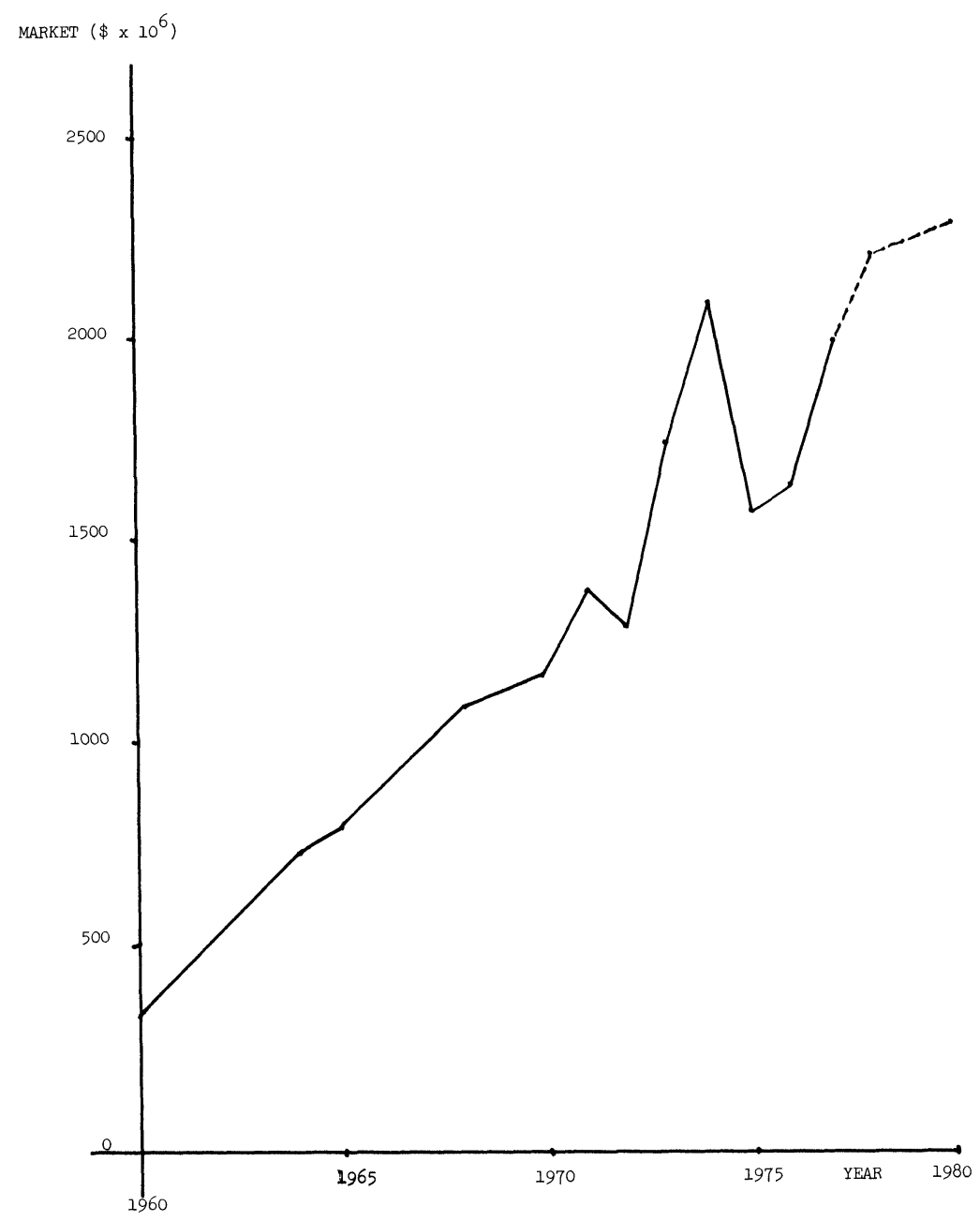

FIGURE 1 World capacitor markets, 1960-1980. (Inflation not allowed for).

\section{GROWTH OF SPECIFIC PRODUCT AREAS WITHIN THE CAPACITOR INDUSTRY}

\subsection{Plastic Film Capacitors}

As previously stated, this is one of the largest growth areas within the capacitor industry due to the replacement of paper as the major dielectric material.

Originally spearheaded by polyester which has continued to be used in large quantities as a dielectric, other materials such as polycarbonate, polystyrene tetraphallate and polypropylene are now used where different dielectric properties are required. (See Ref. 4 for a technical survey of plastics).
3.1.1 A.C. capacitors In the case of polypropylene a strong boost to its development as a dielectric for A.C. applications was given by the banning in practically every country in the world of polychlorinated biphenyl (P.C.B.) as it appears to cause serious environmental pollution.

As this impregnant was used for the majority of capacitors manufactured for A.C. motor run applications and for capacitors used in fluorescent lamps, it was essential that a new type of capacitor was developed in the shortest time possible to meet the requirements of the environmentalists, the electrical requirements of the circuit and the physical shapes and size available for the component. 


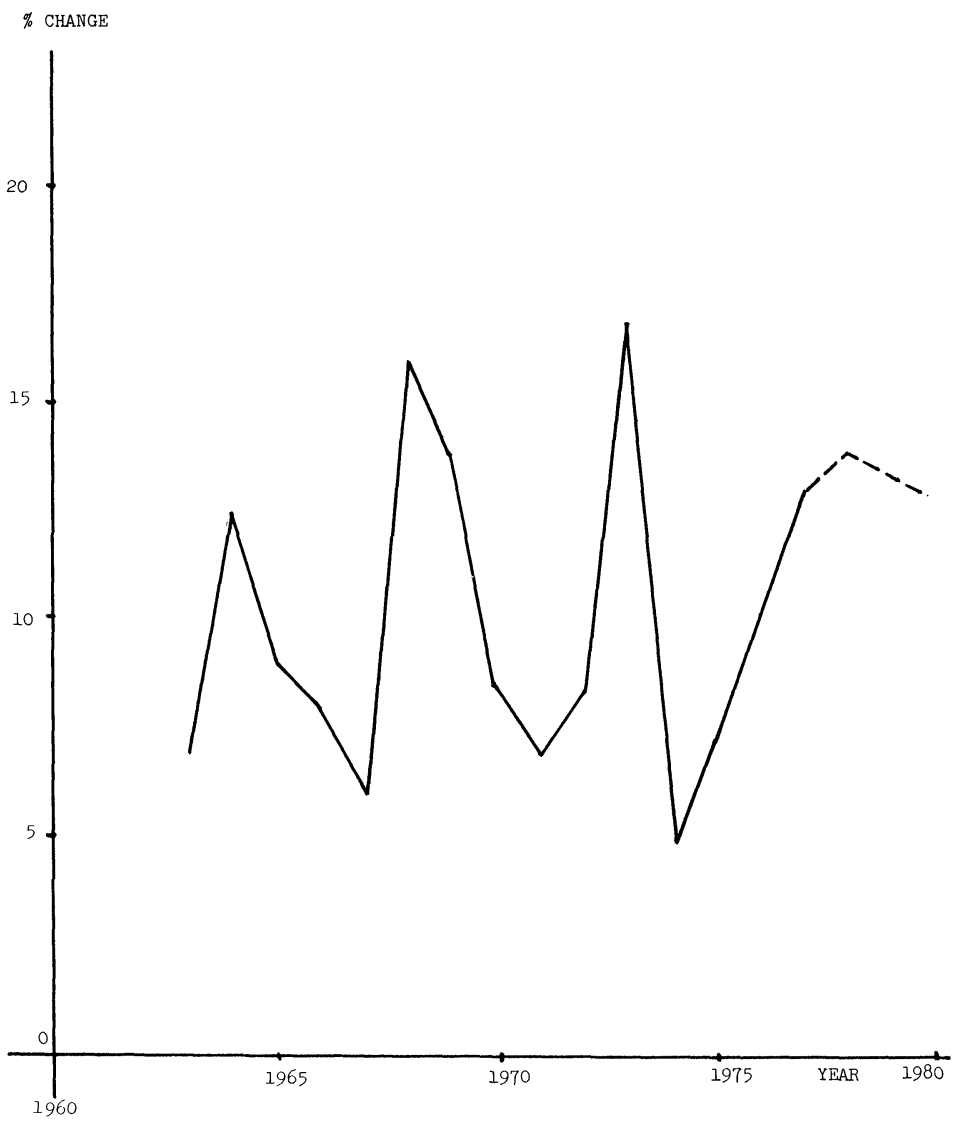

FIGURE 2 Percentage change in world capacitor markets from year to year, 1963-1980.

Satisfactory results have been obtained by a joint development programme between major capacitor manufacturers leading to the introduction of metallised polypropylene non-impregnated capacitors in Europe and the Far East for A.C. voltages up to $440 \mathrm{~V}$ while in the U.S.A., it appears that although dry metallised polypropylene capacitors will be used for a majority of applications, a non-pollutant impregnant may be used where the capacitor has to undergo very strenuous duty cycles.

It is predicted that in the short term, polypropylene is likely to replace paper as a dielectric in all except the larger power capacitors and in areas of very high voltages. With the completion of further research into high voltages applications, it is also predicted that over a period of several years, paper will be replaced entirely by plastic film as a dielectric.

\subsubsection{D.C. capacitors Replacement of paper} dielectric capacitors by metallised plastic film and film plus discrete foil components for D.C. applications started over 15 years ago and has now grown to cover the major part of the electronics industry. Although paper and mixed dielectric capacitors still survive, these are mainly of obsolete designs or for special low volume applications and will gradually be absorbed by the new technology or will die as the equipment into which they are designed becomes obsolete.

An exception to this is the metallised paper capacitor which is still widely manufactured particularly in Europe by some major companies that have developed this technology. However, even in this area, we are seeing companies diversifying into plastic capacitors although, providing the dielectric remains available, it is expected that metallised paper capacitors will be with us for many years.

A great advantage of the change to metallised film capacitors is the reduction in size made possible by the new design and the automation of the manufacturing process. 


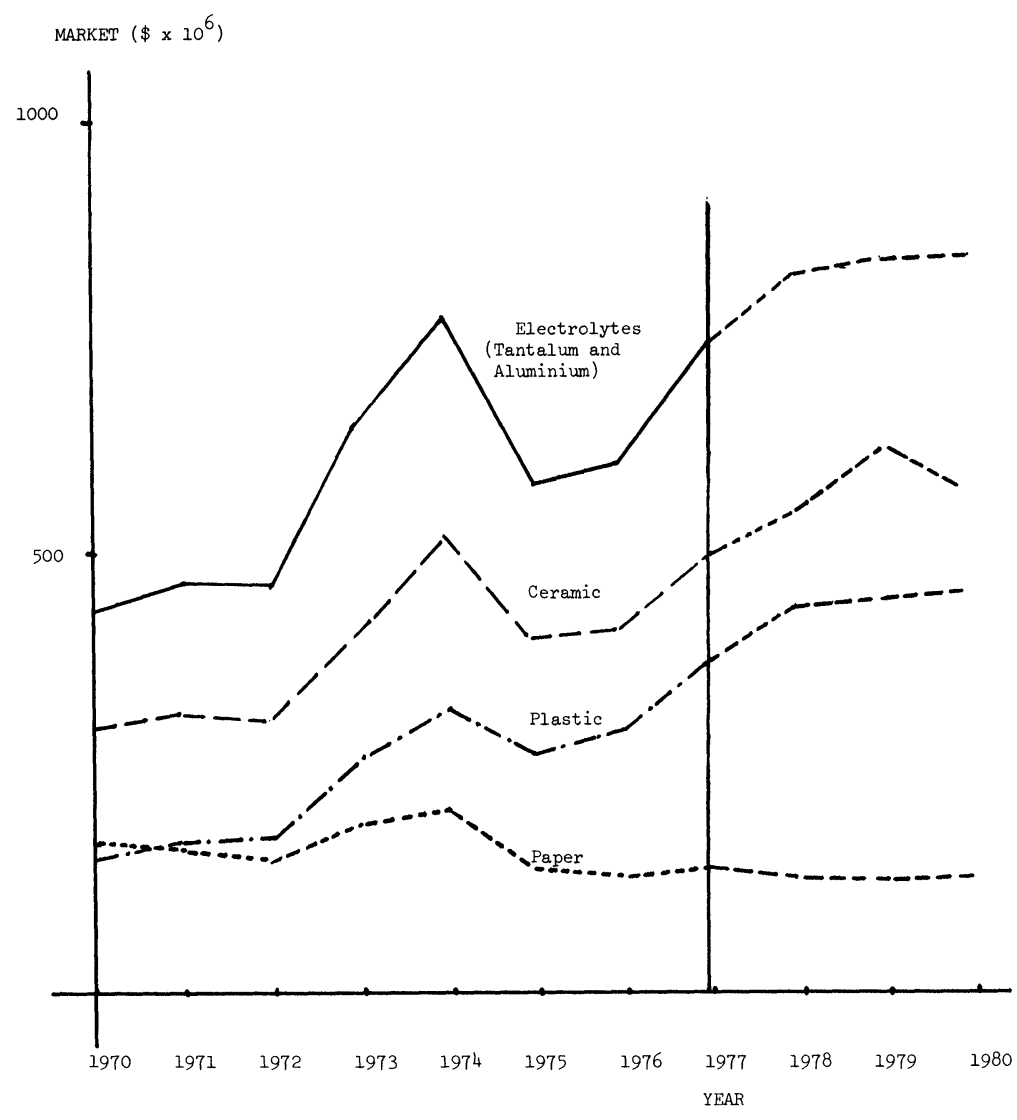

FIGURE 3 World capacitor markets, 1970-1980, by product types. (Inflation not allowed for).

Plessey and other major European manufacturers have pioneered miniaturised designs in radial metallised polyester capacitors that are the equivalent electrically and are similarly priced to monolithic ceramic capacitors. They consist of a radial box type construction that has the $5 \mathrm{~mm}$ and $7.5 \mathrm{~mm}$ lead separation favoured by monolithic ceramic capacitors. The cases are of comparable size. These capacitors have self-extinguishing properties and because they are produced on modern automatic lines (Plessey alone make over two million polyester capacitors a day in four countries) they tend to be more reliable than hand made polyester capacitors. These capacitors can be used for de-coupling, timing, etc. up to as much as $5 \mathrm{MHz}$.

It can therefore be seen that these new polyester capacitors are of great importance. They have impedance characteristics equivalent to the most popular monolithic ceramics and are compatible in size with D.I.P. integrated circuits and other modern active components. It is therefore no longer necessary to use axial capacitors in order to obtain a low profile on a printed circuit board.

Some electrical properties are also superior to existing monolithic capacitors. For example, over a temperature range of -0 to $+85^{\circ} \mathrm{C}$ the capacitance changes far less with temperature and the dissipation factor can also be lower.

Development of plastic dielectrics for specific applications in the field of professional electronics has lead to the production of polypropylene, polystyrene and polycarbonate film capacitors. Capacitor winding techniques are varied according to the electrical characteristics required of the end product. Thus, capacitors can be manufactured as metallised film or film/foil or various combinations of both. By changing the dielectric film and the parameters of assembly of the dielectric and the electrodes, a better made range of capacitors can be produced to match the requirements of a particular type of electronics industry, whether it be in consumer products such as $\mathrm{TV}$, or professional equipment such as computers. 
Consideration is now being given to the replacing where possible, of the more expensive dielectrics such as polycarbonate with polypropylene or polyester. This has led to the development of polypropylene capacitors using a metallised dielectric in conjunction with a discrete film/foil for applications that require a $\mathrm{dv} / \mathrm{dt}$ of $500 \mathrm{~V} / \mu \mathrm{s}$ to $750 \mathrm{~V} / \mu \mathrm{s}$.

It is expected that by 1980 , film capacitors will represent approximately $20 \%$ of the total capacitor market.

\subsection{Ceramic Capacitors}

As with plastic film, ceramic capacitors are one of the major growth areas for the capacitor industry.

With the advent of the transistor and associated solid state devices and the use of much lower voltages in electronic equipment, the disc ceramic came into its own and ceramic capacitors generally have enjoyed an upward growth curve ever since. Considerable investment took place in Europe, U.S.A. and Japan to produce and install automated manufacturing equipment and disc ceramics are produced by the major companies at a rate of many millions per week. Providing the electrical parameters of the disc ceramic can be accepted (i.e. slack capacity tolerance and restricted maximum voltage) the capacitor lends itself to modern circuit requirements because of its small size and compatibility with auto insertion techniques.

By 1980, the ceramic market in the U.S.A. is expected to reach $\$ 200$ million which will represent about $25 \%$ of the total U.S. capacitor market and will be the largest market slice except for electrolytics (aluminium and tantalum added together).

\subsection{Electrolytic Capacitors}

Aluminium electrolytic capacitors have been greatly affected by the disappearance of vacuum tubes and their replacement by solid state devices. The change in requirements in capacitance and voltage ratings coupled with demands by both the consumer and professional electronics industry for smaller products with both higher quality and longer life has brought about the production of the computer grade components on one hand and the cheap, automatically produced plug in electrolytics on the other.

Japanese companies have been in the forefront of the development of automated production of electrolytics to supply the large Japanese radio and TV industry and this has resulted in Japanese manufacturers leading the world in aluminium electrolytic mass production technology. In 1976, approximately six thousand million aluminium electrolytics were produced in Japan of which over one thousand million were exported.

Over the last two years, the size of the product has stabilised, with development being concentrated upon increasing operating temperatures to cope with higher ripple ratings and increasing the frequency of operation for use in switching power supplies. Similarly, there has been no radical size reduction in the various types of tantalum capacitors. Instead, we have seen changes in encapsulation and configuration. Some professional solid tantalum capacitors are now produced with tubes intended for a welded contact instead of the normal type that is suitable for reflow soldering. There has also been an increased demand for wet tantalum capacitors both in axial and 'button' configuration for use in the avionics industry where high capacitance values and very low leakage currents are required.

Electrolytic capacitors represent approximately $37 \%$ of the total capacitor market.

\section{FUTURE DEVELOPMENT WITHIN THE CAPACITOR INDUSTRY}

As with all industrial processes, the capacitor industry is shaped and directed by the pressures placed upon it by its customers, by competition within the industry and by the need to keep individual business profitable.

Of over 500 capacitor manufacturers in the world, the 18 largest contribute over $50 \%$ of the total market volume. The obviously large variation in size of capacitor manufacturing operations is leading to a diversion of manufacturing philosophy within the industry. If a company has huge volume production, the tendency is to withdraw from products having small production quantities and to concentrate all available capital and expertise on a few main line products with very high production volumes. If, on the other hand, a company has a moderate turnover, the trend is to specialise in small volume production, custom built capacitors such as power capacitors, transmitting capacitors, pulse forming networks, etc. Instead of investing large amounts of capital in automated production, this size of company will usually work on a jobbing shop basis concentrating their business on customers requiring specialist components having high quality standards.

\subsection{Product Specialisation}

In order to survive as a profitable business, it is 
becoming increasingly necessary for the major capacitor manufacturers to limit their development and investment programme to one or two major product lines. There are many factors that contribute to this.

Development projects covering new products are becoming more and more sophisticated and therefore very much more expensive. The capacitor industry has never been known to return a high profit margin and therefore the cash available for development work is limited. Add to this the need to produce results within months rather than years and the limited number of qualified development and research engineers available who have this specialised knowledge and it can be easily deduced that priorities in development have to be carefully assigned to major product areas of the business.

When a new product has been satisfactorily developed in the laboratory, a massive capital investment is required before bulk production can commence. Due partly to inflation and partly to the increasing mechanisation and sophistication of manufacturing plant, the capital investment required for new capacitor manufacturing plant has rocketed in the last few years. Plant has to be written off over a relatively short time as manufacturing techniques will have to be updated more or less on a continuous basis in order to keep abreast of world demands.

It is therefore necessary for concentration on bulk quantity production on a two or three shift basis with the aim, if possible, to become the world leader in the products in which the company has decided to specialise, or if this is impossible, to become one of the first three or four major world suppliers of the product.

With the emphasis on specialisation has come a rethink on the type of manufacturing establishment required to manufacture an automated specialised product. In the old days, capacitor factories had a large floor area and employed a considerable labour force to manufacture a large range of labour intensive products. However, the future trend is for a much smaller unit manufacturing perhaps only one or two product ranges on equipment having a high degree of automation on a two or three shift basis and with the labour content reduced to a minimum. This type of operation permits the management to monitor and improve the efficiency of the operation.

A further pressure being applied to the industry is the fact that the major customers for capacitors are increasingly the multi-nationals who, because of their large volume requirements and multiple manufacturing facilities, require multiple source components throughout the world.
This has had two effects on the industry. Firstly, it has caused the major capacitor manufacturers in each product area to get together to produce rationalised product ranges so that from the customer's point of view, their components are interchangeable with their competitors. If major manufacturers' catalogues are examined such as Plessey, Roederstein, Siemens, Rifa, etc., it will be found that in many instances, compatible products have been designed to give the customer multiple sourcing. Secondly, manufacturers have developed multiple sourcing within their own organisations (e.g. Plessey Capacitors are developing multiple sourcing by establishing operations in Scotland, England, Italy, U.S.A., Germany, South America, Australia and the Far East so that an identical product can be offered from all these areas).

\subsection{Automation}

In order to retain a world lead position with a particular product, major capacitor manufacturers must keep up a continual investment programme to update their manufacturing plant and increase the degree of automation used. This process automatically excludes all products for which there is not a very large demand.

Automation is therefore dividing the major capacitor product areas into two parts. Firstly there are the components used principally in the consumer and telecommunications fields where a good standard quality, economic price and large component volume are required. Here we are looking at automatic production lines producing anything from 40 million to 100 million pieces per year per production line.

The significant features here are that, not only must the equipment be capable of dealing with the large volume orders received from automotive equipment or television manufacturers - orders can be for 20 million capacitors at a time - but must also be able to deal with a sufficient production volume to give a satisfactory return on capital investment.

Secondly, there are the lower volume components required in professional electronics where a high quality standard is necessary and the quantities are much lower. This means that only partial automation is possible and the labour content per component rises thus producing much more expensive components.

Normally, a capacitor manufacturing operation produces both consumer and professional components and as these two markets have in the past tended to fluctuate at different times, it permits the production unit to obtain an acceptable work load despite the movement of the market. 
Of course, automation does not come easily. There are about eight companies in the world making automatic machinery for capacitor manufacture but if the capacitor manufacturer wishes to obtain a lead position in a particular product area, it is necessary for him to develop his own manufacturing equipment either by modification of existing machines or the development of new specialist machines.

As previously explained, even the largest companies cannot afford the money or effort to mechanise all forms of capacitor. The Japanese invested primarily in small aluminium electrolytics five years ago but European manufacturers are fast catching up with them.

The Europeans lead the world in the automated manufacture of metallised film capacitors and are still ahead of Japan and the U.S.A. in this field. This technology has been further developed to produce non-impregnated polypropylene capacitors for power applications and this automated technology is expected to maintain its lead in the world market.

With tantalum capacitors, it was the U.S. manufacturers who made large investments in new plant to scale up the production of solid tantalum dipped capacitors.

In ceramics the Americans and Japanese mechanised the production of disc capacitors and are now mechanising the production of monolithic capacitors on a scale well ahead of any European effort.

It is therefore not surprising that the world's largest manufacturers of film capacitors are European, of ceramic capacitors are American and Japanese and of tantalum are American.

\subsection{Quality Requirements}

Apart from the standard requirements for electrical characteristics of capacitance, voltage, etc., pressures are being exerted upon the capacitor industry to produce products that are not hazardous to the environment. With increasing concern being expressed over environmental pollution, many chemicals that are widely used in the industry have had to undergo investigation. The most notable of these is polychlorinated biphenyl which is now banned in most of the world. This has, however, caused a fresh look to be taken at other chlorine compounds used as impregnants as well as many of the chemicals used during encapsulation processes particularly with respect to those used to create flame retardent properties in the component. As this is coupled with an increasing demand for higher working temperatures and nonflammable components, considerable investment must be made by the capacitor manufacturer in chemical research.

\subsection{Size}

"Small is beautiful". This saying applies particularly to the electronics industry. Since the end of World War II miniaturisation of components has taken place that in 1946 would have been considered only possible in the realms of science fiction.

The growth of new industries such as the computer industry, and the in-car entertainment industry, have in particular put pressure on the components industry to produce smaller products while preserving quality and price levels. These requirements have been met by the use of new materials and the automation of product lines capable of rapid handling of small components.

The demand for smaller capacitors has helped to increase the sales of radial lead film capacitors especially when made as a plastic box version rather than dipped. These have the following advantages when used in printed circuit boards (P.C.B.).

a) No exposed leads in the circuit.

b) Well defined dimensions permit more devices per unit area of the P.C.B.

c) They are usually cheaper than axial capacitors.

d) Values easier to read when the capacitor is fitted.

e) Shorter leads means less chance of radiating interference and permits a higher resonant frequency.

f) Strong mechanical construction.

g) Will stand upright without external support during flow soldering.

In both ceramic and tantalum capacitors, great strides in miniaturisation have been achieved with the major product types being radial, dipped capacitors.

In electrolytics, the greatest size reduction has taken place in the production of the radial, plug in type of capacitor.

\subsection{Automatic Insertion of Components}

A growing influence on the development of capacitors is the increasing use of automatic insertion machinery for all types of components. For many years, machines have been available principally from the U.S.A. and Japan that were capable of inserting preselected components onto a printed circuit board at rates up to nine thousand pieces an hour. 
Recently, machines have been developed both in the U.S.A. and Japan that are capable of automatic insertion of radial components at rates of up to four thousand pieces an hour. With the continuously rising cost of labour, the major consumers of electronic components are installing more and more autoinsertion machines.

This is leading to more component rationalisation among capacitor manufacturers as it becomes imperative that their components are suitable for bandoliering for auto-insertion techniques.

Although bandoliering of axial components using two carrying bands has been in existence for many years, radial component auto-insertion has now been developed using a single carrier band which is particularly suitable for many types of component including ceramic, tantalum, polyester and plug in electrolytic capacitors. It has proved particularly suitable in the case of dipped capacitors particularly ceramics as they are suspended from a single band during the manufacturing process and therefore a bandoliered product can be produced at no extra cost.

\section{CONCLUSIONS}

We have, in the course of this article, examined the world capacitor industry and its development trends. Manufacturing and development philosophies have been discussed and the areas of polarisation within the industry highlighted. With these changes it is expected that the industry will continue to experience healthy growth for the foreseeable future.

\section{REFERENCES}

1. C. A. Harper, Handbook of Components for Electronics, Chapter 8, Capacitors, McGraw Hill, N.Y., 1977.

2. Mackintosh Electronic Year Book, Mackintosh Publications, Lond on, 1977.

3. Electronics, 50, pp. 81-104, 1977.

4. W. Goldie, Metallic Coating of Plastics, Vol. 2, Electrochemical Publications Ltd., U.K., 1969.

\section{OTHER SOURCES OF INFORMATION}

Gnostic Concepts Inc.

Electronics Industries Association market data books. Journal of the Electronics Industry. 

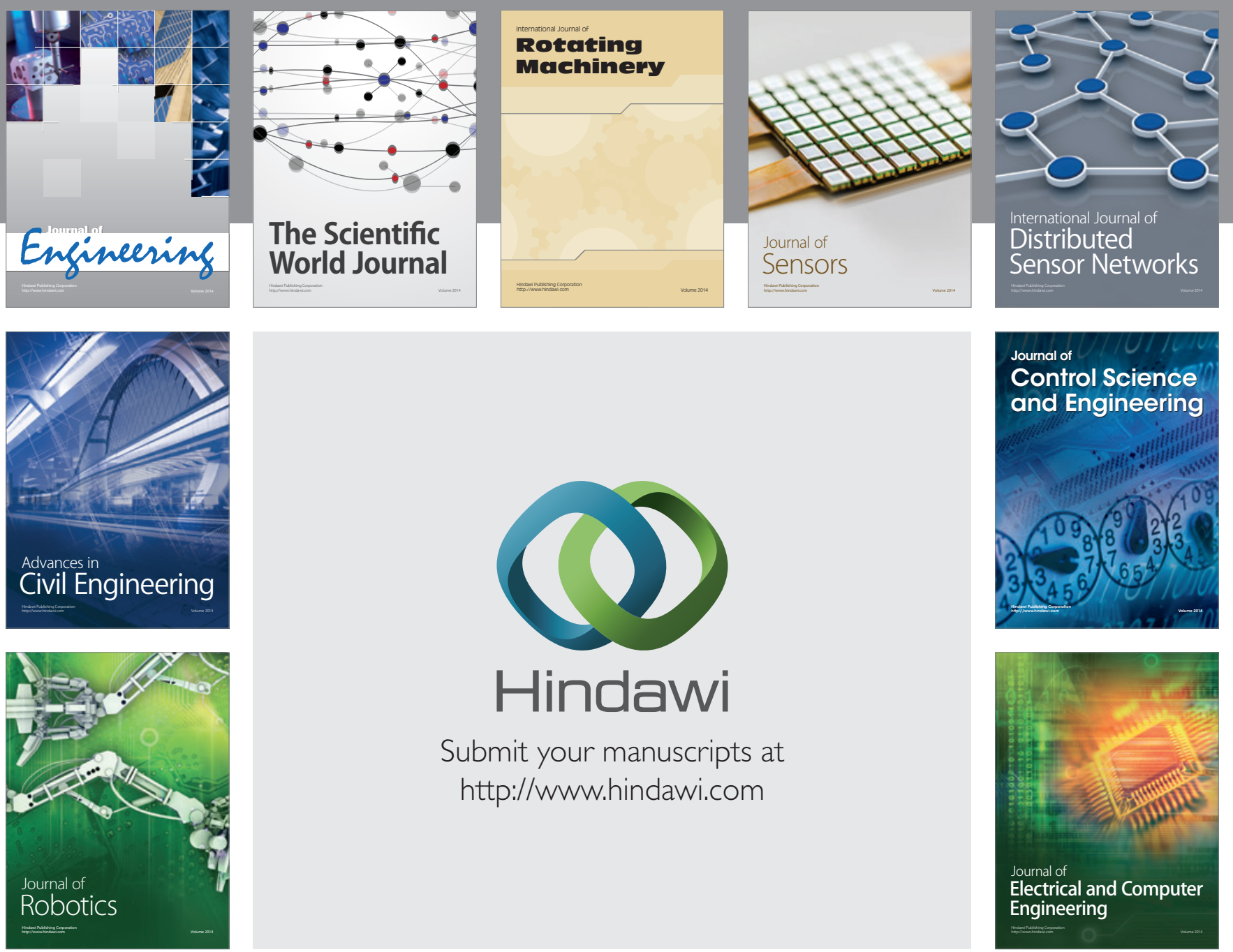

Submit your manuscripts at

http://www.hindawi.com
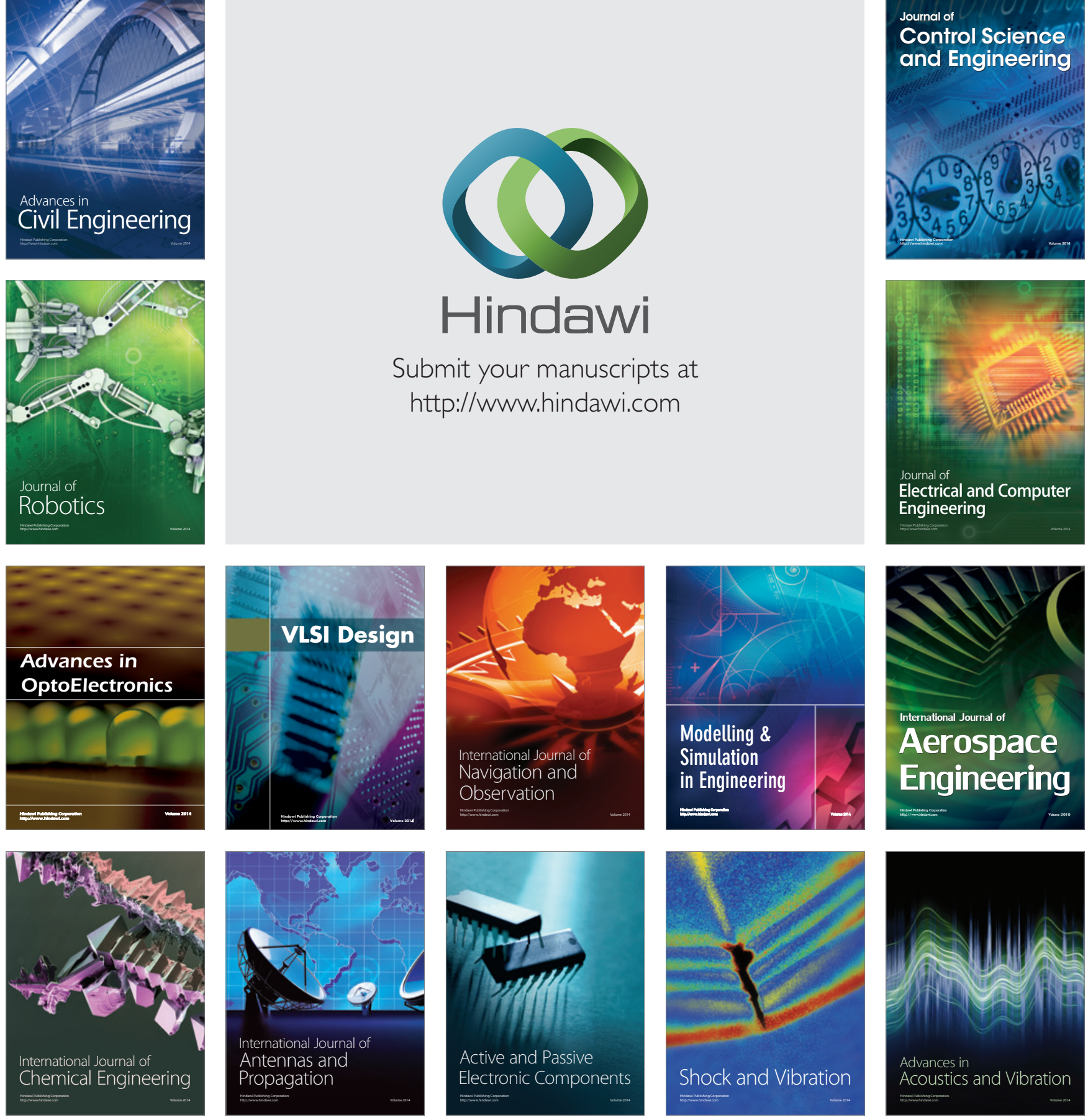